\title{
CHEMO-MECHANICAL MODELLING OF LIME TREATED SOILS
}

\author{
V. Robin ${ }^{1,2}$, O. Cuisinier ${ }^{1}$, F. Masrouri ${ }^{1}$, A.A. Javadi ${ }^{2}$
}

${ }^{1}$ LEMTA - UMR 7563 CNRS, Laboratoire d'Energétique et de Mécanique Théorique et Appliquée, Université de Lorraine, France

${ }^{2}$ Computational Geomechanics Group, Department of Engineering, University of Exeter, United-Kingdom

Abstract. Lime treatment has been widely used to improve mechanical properties of soils.

However, less has been done to account for the effect of the treatment on constitutive relationships. In this study, a comprehensive programme of isotropic consolidation tests and drained triaxial experiments were designed and carried out on saturated specimens of a silt treated with quicklime. The chemical composition in hydrates, portlandite, and carbonates was determined using thermogravimetric analysis and differential thermal analysis. The modifications to the mechanical parameters of the soil were evaluated in the framework of the Cam Clay elastoplastic model. The experimental results revealed that the addition of lime leads to the modification of the critical state. For concentrations in lime higher than $1 \%$, the treated specimens displayed a different normal compression line compared to the untreated state. Chemical analysis revealed the production of cementitious compounds for every concentration tested. A constitutive model was proposed to describe the observed behaviour of lime treated soils in the framework of the Structured Cam Clay. The model accounts for the modifications on the mechanical parameters of the soil. A chemo-mechanical coupling was established between the yield stress and the mass concentration in cementitious compounds.

Keywords: quicklime; mechanical behaviour; chemo-mechanical coupling; constitutive modelling. 


\section{INTRODUCTION}

26 For economic and environmental considerations, engineering companies are highly

27 encouraged to use on site materials to construct earth structures like embankment, river 28 levees, earth dams, etc. For soils with low mechanical characteristics, lime treatment $(\mathrm{CaO})$ is 29 an efficient method to improve their properties and allow their use in geotechnical structures 30 (e.g. Little, 1995). It is of the greatest interest to account for artificial treatments in geotechnical design.

When added to the soil, quicklime reacts with the free water to produce hydrated lime, known as portlandite $\left(\mathrm{Ca}(\mathrm{OH})_{2}\right)$. Then, calcium cations $\mathrm{Ca}^{2+}$ and hydroxides anions $\mathrm{HO}^{-}$are released in the soil, which increase the $\mathrm{pH}$ of the porous medium. Cation exchange process combined with the presence of large amounts of calcium ions adsorbed on the clay particles surface lead to a reduction of the size of the double diffuse layer of the clay particles. This results in the lowering of the repelling forces between clay particles and thereby gives rise to the flocculation of the clay particles. It is generally accepted that cation exchange and flocculation processes occur immediately after the addition of lime, and result in a decrease 40 of the soil plasticity (e.g. Eades and Grim, 1966; Rogers and Glendinning, 1996). Moreover, the addition of lime leads to a high $\mathrm{pH}$ environment (near 12.4), which enables the dissolution of both silica and alumina present in the soil (e.g. North et al., 2008). These later react with the calcium. As a result of these chemical reactions, known as pozzolanic reactions, cementitious compounds such as calcium silicate hydrates (CSH), calcium aluminate hydrates $(\mathrm{CAH})$, and calcium aluminosilicate hydrates $(\mathrm{CASH})$ can be formed (e.g. Metelková et al., 2012; Pomakhina et al., 2012). The formation of these compounds leads to a modification in the soil mechanical properties (e.g. Little, 1995). Many authors have studied the mechanical behaviour of materials treated with lime or cement (e.g. Malandraki and Toll, 2001; Cuisinier et al., 2008; Consoli et al., 2011; Cuisinier et al., 

leads to a modification of the mechanical parameters such as the cohesion, the friction angle, and the yield stress. Improvements obtained with lime treatment regarding tensile strength and Young's modulus have been integrated in the design of pavement (Thompson, 1965). Nevertheless, less has been done to consider these improvements in the design of structures for global stability or settlement analysis. This last issue could be associated with the fact that there is no specific constitutive relationship accounting for the specific aspects of the mechanical behaviour of lime-treated soils, and for the coupling between physicochemical processes and mechanical behaviour. Such relationship is required to account for the treatment in the design of geotechnical structures, in the short term and also to foretell the long term behaviour of earthen structures built with lime-treated soils. Lime treatment induces the formation of cementitious compounds that bind soil particles. Some studies (Leroueil and Vaughan, 1990; Liu and Carter, 2003) have shown that naturally structured soils and artificially treated materials have common mechanical features, treatment appearing to create a "structure" in the soil. In this paper, "structure" refers to the combination of the fabric and the bonding of the soil skeleton (Burland, 1990). Fabric accounts for the arrangement of particles, which depends on the state of compaction, and

67 their geometry.

Several constitutive models have been proposed for structured materials (Gens and Nova, 1993; Cotecchia and Chandler, 2000; Vatsala et al., 2001; Nova et al., 2003; Baudet and Stallebrass, 2004; Lee et al., 2004). Liu and Carter (2002) proposed a Cam Clay based constitutive model for structured materials, adding only three extra parameters to the original Modified Cam Clay (Roscoe and Burland, 1968). Since then several enhancements (Horpibulsuk et al., 2010a; Suebsuk et al., 2011, 2010) have been proposed. Most of these constitutive models use the destructured state as reference to describe the mechanical 
behaviour of the structured soils. The destructured state accounts for the intrinsic parameters of the soil, and especially the geometry of the particles. Artificial cementation arising from the treatment involves chemical reactions that could alter the soil particles. This aspect should be considered to adapt the existing framework to the case of lime stabilised compacted soils. A key aspect of lime stabilization is the fact that the structure, and thus the mechanical behaviour, relies on physicochemical processes that need to be quantified. Based on the soil water transfer method (Zhu et al., 2007), Chiu et al. (2009) used centrifuge method to determine the variation of soil water composition in dredged materials with high water content. A different approach was used in this study to assess the chemical composition of lime treated compacted soils with lower water content. Chemical composition in hydrates and portlandite in cement and concrete was successfully determined using thermogravimetric analysis (TGA) and differential thermal analysis (DTA). Some studies (Horpibulsuk et al., 2010b; Maubec, 2010) have shown the suitability of this method to determine the chemical modifications following a lime treatment. The objective of the paper is to investigate the couplings between mechanical behaviour and physicochemical processes, and then to 90 introduce these aspects in a constitutive relationship.

To account for the treatment in the structure design, a chemo-mechanical coupling is required to predict the mechanical improvements resulting from the addition of a given amount of lime. This implies a good understanding of the mechanical behaviour of lime treated soils and

94 of the chemical modifications arising from the treatment. To this end, the paper aims at shedding light on three aspects:

a) How can the effects of a lime treatment on a material and its consequences on the mechanical properties be described?

b) How can a chemo-mechanical coupling be established between the mechanical improvements and the chemical modifications? 
c) How can a lime treated soil be modelled?

\subsection{Tested soil and specimens preparation}

103 The material selected in this study is a silt from the East part of France. The mineral

104 composition is as follows: quartz (55\%), kaolinite (12\%), feldspar (11\%), illite (10\%), 105 montmorillonite (4\%), chlorite (1\%), goethite (6.4\%), and carbonates $(0.6 \%)$. The lime 106 fixation point is near $1 \%$ and was determined according to the ASTM Standard D6276

107 (2006). Before proceeding to the moulding of the specimen, the material was first heated at $60^{\circ} \mathrm{C}$ and then sieved to get particles smaller than $2 \mathrm{~mm}$. The main characteristics of the soil

109 are listed in Table 1.

110 Five concentrations in quicklime were considered in this study: 0, 0.5, 1, 2, and 5\% expressed 111 on a soil dry weight basis. The non-treated specimen $(0 \%)$ was used as reference to assess the 112 mechanical and the chemical modifications arising from the treatment.

113 All the specimens used for the mechanical characterisation of the soil, with or without

114 treatment, were prepared at the same moisture content and dry density. Indeed, the optimal 115 moisture content and maximum dry density of the silt used in this study were not 116 significantly modified by the lime-treatment (Table 2). Therefore, all the specimens have 117 been prepared at the same mean initial water content of $20 \%$ and a dry density of $1.68 \mathrm{Mg} . \mathrm{m}^{-}$

$118{ }^{3}$. Thus, any modification of the mechanical behaviour of the soil after treatment can be 119 attributed mostly to structure modification, i.e. fabric and bonding, but not to density.

120 The soil was first prepared at the target water content. After an equilibration period of several 121 days, quicklime was added to the soil, both being mixed thoroughly until a homogenous mixture was obtained. Before the specimens were compacted, the quicklime-soil mixture was

123 sealed in hermetic plastic bags for one hour before compaction. Then, $35 \mathrm{~mm} \times 70 \mathrm{~mm}$ triaxial 124 specimens were statically compacted up to target the dry density. After these steps, the actual 
125 water content of the specimens was determined. It varied between $19.6 \%$ and $20.2 \%$. The

126 specimens were then wrapped in plastic bags to prevent any exchange with the atmosphere,

127 and a curing time of 28 days was respected.

\section{$128 \quad$ 2.2. Drained triaxial experiments}

129 To determine the shape of the yield function, three kinds of stress path were performed in this

130 study: isotropic consolidation, drained paths $\left(\sigma_{3}^{\prime}\right.$ constant), and same stress ratio paths

$131 \quad\left(\eta=p^{\prime} / q=0.39\right)$

132 Saturation was achieved by first creating an upward water flow through the specimen. This

133 was achieved by applying a pressure gradient between the bottom and the top of the

134 specimen. Deaerated water was used to maximize the dissolution of air. Pore pressure was

135 then increased in three stages (Table 3) while maintaining a constant effective mean stress.

136 After every triaxial experiment, saturation of the specimen was checked by determining the

137 degree of saturation with paraffin according to the ASTM Standard D7263-09 (2009).

138 To ensure full drainage of the specimens during the experiments, filter paper strips were

139 applied to the surface of the specimens. Low rates of consolidation and axial deformation

140 were chosen in order to generate small excess of pore pressure. An external probe was used

141 to measure accurately the pore pressure at the bottom of the specimen during shearing.

142 For isotropic consolidation, a rate of 3.47 Pa.s ${ }^{-1}$ was chosen and specimens were consolidated

143 up to a total effective stress of $3,320 \mathrm{kPa}$. Validation tests were performed to verify that there

144 was no excess pore pressure in the specimen under this rate.

145 Triaxial compression tests were carried out with an axial displacement rate of $2.46 \mu \mathrm{m} . \mathrm{min}^{-1}$,

146 leading to an axial deformation of about 5\% per day. Validation tests have confirmed the

147 suitability of this rate. All the experiments were performed following the procedure described 
148 in the ASTM Standard D7181-11 (2011). The initial conditions of the specimens are given

149 Table 4.

$150 \quad$ 2.3. Monitoring of the physicochemical reactions

151 Lime can react with soil particles to produce only three different chemical compounds:

152 portlandite, hydrates (cementitious compounds $\mathrm{CAH}, \mathrm{CSH}$, and $\mathrm{CASH}$ ), and carbonates.

153 Portlandite is produced by the hydration of quicklime introduced in the material, according to

154 the following reaction:

$$
\mathrm{CaO}_{(s)}+\mathrm{H}_{2} \mathrm{O}_{(\mathrm{l})} \rightarrow \mathrm{Ca}(\mathrm{OH})_{2(a q)}+1140 \mathrm{~kJ} / \mathrm{kg} \text { of } \mathrm{CaO}
$$

155 Dissociation of portlandite induces release of hydroxide anions, thus increasing the $\mathrm{pH}$. Once

156 a suitable $\mathrm{pH}$ is reached in the porous medium, portlandite is consumed by pozzolanic

157 reactions to produce hydrates.

158 Due to the high sensibility of lime with carbon dioxide, we also considered the evolution in

159 carbonates in the specimens. Carbonates are produced by reaction of quicklime and carbon

160 dioxide according to the following reaction:

$$
\mathrm{CaO}_{(s)}+\mathrm{CO}_{2(g)} \rightarrow \mathrm{CaCO}_{3(s)}
$$

161 Therefore, to monitor the progress of the physicochemical processes in the specimens, it is

162 necessary to determine the amount of portlandite, hydrates, and carbonates.

163 Thermogravimetric analysis (TGA) consists of measuring the mass loss of a specimen as a

164 function of the increasing temperature. This test is completed with a differential thermal

165 analysis (DTA), which compares any temperature difference between the specimen and an

166 inert reference (MacKenzie, 1970). Each peak on the curves is correlated to a chemical

167 compound. Using the associated mass loss, the mass concentration of the species can be 168 estimated (Mackenzie, 1972). 
169 TGA/DTA analysis was first used successfully to determine the chemical composition of 170 cements and concretes in hydrated products, portlandite, and carbonates. Some studies have

171 shown that the decarboxylation processes of these three compounds were associated with

172 three temperature domains (Das et al., 1996; Saikia et al., 2002; Alarcon-Ruiz et al., 2005).

173 Recent studies have applied TGA/TDA analysis on artificially treated soils to assess the mass

174 concentration in portlandite (unreacted lime), cementitious compounds, and calcium 175 carbonates in artificially treated specimens (Horpibulsuk et al., 2010b; Maubec, 2010).

176 The procedure for the determination of the chemical composition is illustrated on Figure 1. 177 TGA/DTA analysis provides three different curves: the variation of the energy (TDA), the 178 mass loss (TG), and the first derivative of the weight loss (DTG). First, TDA and DTG 179 results were used to determine accurately the three temperature domains (Table 5).

180 Each peak on the DTG curve (Figure 1) is associated to a variation of the weight loss and 181 corresponds to the decarboxylation of a chemical compound. The two temperatures 182 delimitating the peak correspond to the temperature domains, and the chemical compound is 183 assumed to have completely disappeared when the upper temperature limit was reached. 184 Therefore, the variation of weight (TG curve) between these two temperatures gives the mass 185 of the chemical compound. Analyses were performed using a NETZSCH STA 409 PC/PG 186 device. The accuracy of the TGA weighing scale was $0.01 \mathrm{mg}$.

\section{RESULTS}

188 The experiments performed in this paper aimed: 1) to determine the effects of the quicklime 189 on the intrinsic parameters of soils, 2) to assess the shape of the yield function in order to 190 choose the most suitable model for lime-treated soils, and 3) to measure the concentrations in 191 portlandite, hydrates, and carbonates of a lime-treated specimens. 


\subsection{Mechanical behaviour}

\subsubsection{Isotropic consolidation}

194 To assess the effects of the treatment on the yield stress, isotropic consolidation tests were

195 performed on $0,0.5,1,2$, and 5\% lime-treated specimens. For concentrations greater than

$1961 \%$, three isotropic tests were carried out to ensure the highest representativeness. Only one

197 result is reported in Figure 2. The yield stress was determined using Casagrande's method.

198 Yield occurred for an effective mean stress of $177 \mathrm{kPa}$ for the untreated specimen (Figure 2).

199 When lime was added to the soil, the yield stress was increased even for low lime content of $2000.5 \%$. The evolution of the yield stress as a function of the lime content is given in Figure 3.

201 For concentrations between $0.5 \%$ and $2 \%$, the gradient of the curve was significantly

202 increased. Above 2\% the slope decreased, and as concentration increased, yield stress value seemed to approach $2,000 \mathrm{kPa}$. One can note that there exists a one-to-one correspondence between the lime content and the resulting yield stress after 28 days of curing.

At yield the treated soil displayed higher specific volume compared to the reference state (Figure 2). This could be due to the structure. When the effective mean stress reached the yield stress, the additional specific volume began to decrease as the effective mean stress was increased until a new normal compression line was reached, parallel to the one of the nontreated state. This decrease of the additional specific volume corresponds to the loss of the structure. Only $0.5 \%$ lime treated specimen has shown to completely lose the additional

211 specific volume at high mean stresses. In this case, the normal compression line matched the

212 one of the non-treated state. For lime contents greater than $1 \%$, specimens did not appear to converge to the non-treated state for mean effective stresses lower than $3,320 \mathrm{kPa}$. At some

214 point, a secondary normal compression line, different from the non-treated state but still

215 parallel, seems to be reached. This feature is particularly noteworthy for the $1 \%$ treated 216 specimen. The $2 \%$ and 5\% lime-treated specimens have shown such significant $9 / 25$ 
217 improvements in mechanical properties that this feature could not be seen because of the

218 limits of the applied pressure in triaxial cell $(3,500 \mathrm{kPa})$.

219 3.1.2. Shear behaviour

220 Drained triaxial experiments were performed to assess the shape of the yield function and the

221 gradient of the critical state line. Different stress paths and pre-consolidation pressures were

222 performed on $0,1,2$, and $5 \%$ lime-treated specimens.

223 The shear behaviour of the non-treated specimens (Figure 4a) was significantly improved

224 with 5\% lime treatment (Figure 4b). For an isotropic pre-consolidation pressure of $245 \mathrm{kPa}$,

225 the yield locus of the reference state was reached for a deviatoric stress of $400 \mathrm{kPa}$. With 5\%

226 of lime, this value was increased up to $1,250 \mathrm{kPa}$.

227 As the confining pressure was increased, one can see that contraction behaviour was 228 gradually observed. This feature was particularly marked for the 5\% lime-treated specimens

229 (Figure 4b). For a confining pressure of $20 \mathrm{kPa}$, the specimens had significant dilation 230 behaviour. As the confining pressure increased, the specimens started to exhibit a contraction 231 behaviour.

\section{$232 \quad 3.2$. Yield loci for lime-treated soils}

233 Yield loci and critical states were determined from the previous results and plotted in the $234\left(p^{\prime}, q\right)$ plane (Figure 5). Results from the same stress ratio paths $(\eta=0.39)$ were also 235 included.

236 To use these results in a constitutive model, yield loci and critical states were determined 237 based on the critical state theory (Muir Wood, 1991). Yield was assumed to occur when 238 plastic deformation appeared $\left(\varepsilon_{q}^{p}>0\right)$, and critical state was reached when:

$$
\frac{\partial p^{\prime}}{d \varepsilon_{q}}=\frac{\partial q}{d \varepsilon_{q}}=\frac{\partial v}{d \varepsilon_{q}}=0
$$


239 The elastic domain showed to be significantly increased with increasing the lime content,

240 without any significant anisotropic behaviour, and the critical state lines appeared to be

241 modified with the treatment. The gradient and the y-intercept of the critical state lines both

242 increased with increasing the amount in lime. The results appear to be well described by the

243 Modified Cam Clay model.

\section{3.3. Chemical analysis}

245 The results of TGA/DTA tests to measure the chemical composition in portlandite, hydrates, 246 and carbonates on $0,0.5,1,2$, and $5 \%$ lime treated specimens are plotted in Figure 6 . The y247 axis values correspond to the variation of mass compared to the untreated specimen.

248 The chemical composition of the soil appears to be modified after addition of lime and a 249 curing time of 28 days. Concentration in portlandite is increased only for lime contents 250 greater than $0.5 \%$. The latter is used by pozzolanic reactions to produce cementitious 251 compounds. For a concentration of $0.5 \%$, all the portlandite produced by the hydration of the 252 quicklime was used by pozzolanic reactions.

253 Concentration in hydrates was increased for all the lime contents. It is worth to note that there

254 is a one-to-one correspondence between the lime content and the mass concentration in 255 hydrates. The fact that neo-portlandite is measured for high lime contents means that pozzolanic reactions are unfinished and concentration in hydrates is likely to evolve if the curing time is extended.

258 Concentration in carbonates revealed to be increased only for high lime contents. Probability 259 of carbonation is higher at high lime contents and this could explain the sudden formation of 260 carbonates. It is more likely that these new carbonates are the result of the reaction of the unhydrated lime with the atmospheric carbon dioxide.

\section{DISCUSSION}


263 In the first part of the discussion section, the influence of lime on the mechanical properties

264 of soil is discussed. Moreover, a quantification of the physicochemical processes induced by

265 lime-treatment after 28 days of curing is provided. The main objective of the second part of 266 the discussion section is to highlight the coupling between the mechanical behaviour and the

267 amount of the different compounds formed during the curing period, and to propose an 268 equation for the coupling. In the last part, a framework to account for the effects of the 269 treatment on the intrinsic parameters is proposed.

\subsection{Influence of lime on mechanical parameters}

271 Lime has appeared to modify the mechanical behaviour of the soil, and parameters like the

272 position of the virgin consolidation line and the slope of the critical state line, M. Following 273 the definition proposed by Burland (1990), "structure" consists of the combination of the cementation and the fabric. In the case of structured soils, Leroueil and Vaughan (1990) showed that isotropic consolidation induced a progressive loss of structure at yield. After total loss of structure, the normal compression line of the structured soil converges to that of

277 the same soil prepared in a remoulded state before compression.

278 In the case of a treated soil with quicklime, this assumption was only valid for a soil treated with $0.5 \%$ of quicklime. Isotropic consolidation results revealed a full loss of the structure for $0.5 \%$ lime treated specimens, which displayed the same virgin consolidation line as the nontreated specimens at a mean stress value of $1,340 \mathrm{kPa}$. However, for concentrations greater or equal than $1 \%$ it could be assumed that the position of the virgin consolidation line following the destructuration is shifted. This feature is usually controlled by the fabric, and especially by the geometry of the particles. Therefore, one may assume that the geometry of the particles is modified by the treatment and is lime content-dependant. This observation is corroborated by the drained triaxial test results, which revealed a modification of the critical 
of the critical state line, M, is a direct function of the angle of friction (Schofield and Wroth, 1968) and describes the relationship between the particles and their geometry. A modification of $\mathrm{M}$ (Table 6) implies a modification of the angle of friction, and therefore of the geometry of the particles (Stocker, 1974; Wissa, 1965). Therefore, in the framework of the lime-treated soils, our results show that these mechanical parameters are modified.

293 Parameters like $\mathrm{M}$ and the normal compression line are considered as intrinsic and invariable in the framework of naturally structured soils (Liu and Carter, 2002). For these materials, reconstituted state is used as reference to assess the mechanical improvements due to the structure. In this case, the soil particles have already experienced cementation processes. The soils particles of the untreated state have not been in contact with lime and hence no

298 modification of their geometry has occurred. From this point of view, the use of the mechanical parameters of the non-treated state as reference appears to be inappropriate to assess the effects of the treatment. This is important to describe the improvements, but not enough to fully describe the mechanical behaviour of treated soils. To do this, an intermediate state appears to be required, the destructured state of the lime treated soil. This state would account for the effects of the treatment on the mechanical parameters.

304 These results have showed that mechanical parameters of a soil are modified with the addition of quicklime. Therefore, it appears of the greatest interest to compare those with the chemical modifications arising from the treatment.

\subsection{Correlation between physicochemical processes and yield stress}

308 It has appeared that lime treatment modified the nature of the soil by altering parameters 309 classically considered as intrinsic. In the light of these results and using the approach 310 proposed by Chiu et al. (2009), the yield stress was chosen as the mechanical coupling 311 parameter. Apart from controlling the size of the initial yield function in most of the

312 constitutive models, there is a one-to-one correspondence between the lime content and the 
313 resulting yield stress. The mechanical results and the chemical compositions are plotted in a

314 scatterplot matrix (Figure 7) to assess the trends between the yield stress and the mass

315 concentration in cementitious compounds, portlandite, and carbonates.

316 The trends between the yield stress and the portlandite, and carbonates and hydrates are given

317 in Figure 7. The results show a linear correlation between the yield stress and the portlandite.

318 Hydrates also appear to be linearly correlated to the yield stress. The production of hydrates

319 was noted for every lime content and a one-to-one correspondence with the lime content. A

320 second trend can be noticed between the yield stress and the portlandite. Chemical analysis

321 revealed that all the portlandite has been consumed by pozzolanic reactions for low lime-

322 contents $(<0.5 \%)$. However, mechanical results showed that this lime-content is enough to

323 increase the yield stress. Therefore, portlandite cannot be considered as a relevant parameter

324 for a chemo-mechanical coupling.

325 Production of carbonates was only observed for concentrations greater than $2 \%$, but 326 mechanical improvements can be measured for small lime contents. Maubec (2010) has

327 shown that the contribution of the carbonates in the mechanical behaviour can be neglected.

328 For the same reasons as the portlandite, carbonates are not suitable for a chemo-mechanical 329 coupling. Lime can be easily carbonated in contact with $\mathrm{CO}_{2}$ (Equation 2).

330 In the light of these observations, mass concentration in hydrates is the only parameter 331 systematically modified by the addition of lime and presenting a one-to-one correspondence

332 with the lime content. Since yield stress has also a one-to-one correspondence with the lime 333 content, a coupling between these two parameters appears to be the most relevant choice.

334 In order to establish a coupling, a relationship was established between yield stress and the 335 mass concentration in hydrates. To model accurately a lime-treated soil, the regression 336 function must fulfil the following criteria: 
(a) The point of lime fixation describes the minimum lime-content required to measure mechanical improvements. Thus, for low concentrations in hydrates $(<0.05 \%)$, regression function must show a low gradient.

(b) Above a critical lime content, yield stress does not increase anymore (Rotta et al., 2003). To account for this feature in the coupling, the interpolation function must converge to a finite value for high concentrations in hydrates.

343 To account for these two conditions, we chose a generalised logistic function (also known as

344 Richards's curve) of the form:

$$
\forall \Delta m_{h} \in \mathbb{R}^{+} f\left(\Delta m_{h}\right)=p_{y, \text { min }}+\left(p_{y, \text { max }}-p_{y, \text { min }}\right) \cdot \frac{1}{1+e^{-\beta\left(\Delta m_{h}-\Delta x\right)}}
$$

345 with:

- $p_{y, \min }$ The lower asymptote

- $p_{y, \max }$ The upper asymptote

- $\beta$ The growth rate

- $\Delta x \quad \Delta m_{h}$ value for which the first derivative is maximum and $\frac{d f^{2}}{d^{2} \Delta m_{h}}=0$

346 Using a non-linear least square method, the 4 variables $p_{y, \min }, p_{y, \max }, \beta$, and $\Delta x$ were

347 calculated to determine the optimal set of parameters (Table 7) based on the results of the

348 isotropic tests. For lime concentrations greater than $1 \%$, three isotropic tests were performed

349 to reduce the error. The interpolation appears to satisfactorily describe the results (Figure 8)

350 and fulfil the conditions (a) and (b).

351 The same procedure can be applied to link the mass concentration in hydrates with the lime

352 content. If introduced in the equation 7, this will result in a direct coupling between the

353 amount in lime introduced in the soil and the resulting yield stress. This correlation is allowed 
354 since there is a systematic one-to-one correspondence between all the variables, which proves that a robust coupling between the mechanical behaviour and chemical composition exists.

\subsection{Modification of the Structured Cam Clay model for application on lime treated soils}

Several studies (Leroueil and Vaughan, 1990; Liu and Carter, 2003) have shown that naturally structured soils exhibit similar behaviour to artificially treated materials. Under

359 isotropic consolidation, structured and treated soils display at yield a higher void ratio 360 compared to the remoulded/untreated state (Callisto and Rampello, 2004; Coop and

361 Atkinson, 1993). This additional void ratio tends to disappear as the mean effective stress is 362 increased to finally match the behaviour of the remoulded/untreated state (Burland et al., 363 1996). For drained experiments, Leroueil and Vaughan (1990) noted that a structured 364 material exhibits a rate of maximum dilatation after the peak while this occurs before the 365 peak for a non-structured material. Based on these considerations and the results of this study, one can assume that naturally structured soils and lime treated materials have a similar mechanical behaviour for both isotropic and shear stresses.

368 We propose in this paper a simple modification to the Structured Cam Clay model (SCCM)

369 (Liu and Carter, 2002) to account for the effects of lime treatment on the intrinsic parameters.

370 The SCCM was originally designed for naturally structured soils, but the results prove that it

371 can be applied to lime treated specimen, provided that a modification is implemented to 372 introduce the secondary normal compression line for lime treated materials.

373 The SCCM models structured soils by introducing an additional void ratio $\Delta e$ to the Cam

374 Clay equation of the void ratio as:

$$
e=e^{*}+\Delta e=e^{*}+\Delta e_{i}\left(\frac{p_{y, i}^{\prime}}{p^{\prime}}\right)^{b} \stackrel{p^{\prime} \rightarrow+\infty}{\longrightarrow} e^{*}
$$

375 where:

- $e^{*}$ is the void ratio for the reconstituted soil, 

ratio can be written as follows:

$$
\Delta e=\left[\left(\Delta e_{i}-e_{c}\right)\left(\frac{p_{y, i}^{\prime}}{p^{\prime}}\right)^{b}\right]+e_{c} \stackrel{p^{\prime} \rightarrow+\infty}{\longrightarrow} \Delta e_{c}
$$

385 This formulation ensures the convergence toward the destructured state (intermediate state), rather than the untreated state. This additional parameter $\Delta e_{c}$ can be measured from the same 387 isotropic test used for the determination of $e_{i}$ and $p_{y, i}^{\prime}$. In the case where $\Delta e_{c}=0$, 388 389 equation (5) reverts back to the formulation of the MSCC. For use in constitutive modelling equation (5) can be written in an incremental form:

$$
d v=-\lambda \frac{d p^{\prime}}{p^{\prime}}-\left(\Delta e_{i}-\Delta e_{c}\right) \cdot\left(p_{y, i}^{\prime}\right)^{b} \cdot b \cdot d p^{\prime} \cdot\left(p^{\prime}\right)^{-b-1}
$$

390 The first part is the classic incremental form of the normal compression line from the Cam

391 Clay model and describes the untreated state. The second part adds the effects of the structure as an additional void ratio.

393 The suitability of this formulation for the $1 \%$ lime treated specimen of this study is given in 394 Figure 9. Parameters used for the simulation are given Table 8. 
399 This study has shown the potential of lime treatment to improve the mechanical properties of

400 the materials initially unsuitable for geotechnical structures. Thus, a chemo-mechanical

401 coupling to account for the treatment in the design is of the greatest interest.

402 This paper aimed first to describe in details the effects of lime on the mechanical behaviour

403 of a soil and also on parameters usually considered as constant. The results have shown that

404 there was an improvement of the mechanical parameters due to the chemical reactions

405 occurring after the addition of the lime. For lime contents greater than $1 \%$, the specimens

406 converged toward a normal compression line different from the untreated state but parallel to

407 it. Therefore, in the framework of the lime treated soils, the mechanical parameters of treated

408 soils could be different from those of the untreated state.

409 The chemical composition of lime treated specimens has been successfully assessed using

410 thermogravimetric and thermodifferential analyses. The results have shown that

411 concentrations in cementitious compounds and portlandite increased with the lime content.

412 They permitted to explain the mechanical results and especially the modification of some

413 parameters such as the angle of friction. The production of the cementitious compounds

414 involves several preliminary reactions where soil particles experience dissolution due to the

415 high $\mathrm{pH}$. From this point of view, the nature of soil is seriously altered, leading to an

416 evolution of the mechanical parameters. Chemical results revealed that cementitious

417 compounds were produced for every concentration tested. A chemo-mechanical coupling was

418 established using a logistic function between the amount of cementitious compounds and the

419 yield stress. The proposed equation appears to describe accurately the observations, and

420 ensures a one-to-one correspondence between the mass concentration in cementitious

421 compounds and the yield stress. 
422 A modification of the formulation of the Structured Cam Clay model was proposed by 423 introducing a new parameter $\Delta e_{c}$ describing the position of the second normal compression 424 line. Simulations proved the suitability of the new formulation for use in constitutive 425 modelling.

426 The proposed coupling may be used to account for the treatment in the design of geotechnical 427 structures. However, one must be aware of the durability of the treatment. The bonding 428 structure resulting from chemical reactions occurring at high $\mathrm{pH}$ environment, and treated materials are often subjected to environmental conditions. For example, in the event of a 430 continuous rainfall, water flow may occur changing the $\mathrm{pH}$ environment and altering the 431 chemical equilibriums. This would result in the dissolution of the cementitious compounds 432 and, therefore, in the extinction of the bonding structure. It is thus important to assess the durability for the treatment in the design of geotechnical structures.

\section{REFERENCES}

Alarcon-Ruiz, L., Platret, G., Massieu, E., Ehrlacher, A., 2005. The use of thermal analysis in assessing the effect of temperature on a cement paste. Cem. Concr. Res. 35, 609-613. doi:10.1016/j.cemconres.2004.06.015

ASTM Standard D6276, 2006. Standard Test Method for Using pH to Estimate the Soil-Lime Proportion Requirement for Soil Stabilization. pp. 1-4. 
443 ASTM Standard D7263-09, 2009. Standard Test Methods for Laboratory Determination of

444 Density (Unit Weight) of Soil Specimens. ASTM International, pp. 1-7.

445 doi:10.1520/D7263-09

446

447

448

449

450

451

452

453

454

455

456

457

458

459

460

461

462

463

Baudet, B., Stallebrass, S., 2004. A constitutive model for structured clays. Géotechnique 54, $269-278$

Burland, J.B., 1990. On the compressibility and shear strength of natural clays. Géotechnique 40, 329-378.

Burland, J.B., Rampello, S., Georgiannou, V.N., Calabresi, G., 1996. A laboratory study of the strength of four stiff clays. Géotechnique 46, 491-514. doi:10.1680/geot.1996.46.3.491

Callisto, L., Rampello, S., 2004. An interpretation of structural degradation for three natural clays. Can. Geotech. J. 41, 392-407. doi:10.1139/T03-099

Chiu, C.F., Zhu, W., Zhang, C.L., 2009. Yielding and shear behaviour of cement-treated dredged materials. Eng. Geol. 103, 1-12. doi:10.1016/j.enggeo.2008.07.007

Consoli, N.C., Lopes, L. da S., Prietto, P.D.M., Festugato, L., Cruz, R.C., 2011. Variables Controlling Stiffness and Strength of Lime-Stabilized Soils. J. Geotech. Geoenvironmental Eng. 137, 628-632. doi:10.1061/(ASCE)GT.1943-5606.0000470

Coop, M.R., Atkinson, J.H., 1993. The mechanics of cemented carbonate sands. Géotechnique 43, 53-67.

Cotecchia, F., Chandler, R.J., 2000. A general framework for the mechanical behaviour of clays. Géotechnique 50, 431-447. 
464 Cuisinier, O., Auriol, J.-C., Le Borgne, T., Deneele, D., 2011. Microstructure and hydraulic 465 conductivity of a compacted lime-treated soil. Eng. Geol. 123, 187-193.

466 doi:10.1016/j.enggeo.2011.07.010

467

468

469

470

471

472

473

474

475

476

477

478

479

480

481

482

483

484

Cuisinier, O., Masrouri, F., Pelletier, M., Villieras, F., Mosser-Ruck, R., 2008. Microstructure of a compacted soil submitted to an alkaline PLUME. Appl. Clay Sci. 40, 159-170. doi:10.1016/j.clay.2007.07.005

Das, S.K., Mitra, A., Das Poddar, P.K., 1996. Thermal analysis of hydrated calcium aluminates. J. Therm. Anal. Calorim. 47, 765-774.

Eades, J.L., Grim, R.E., 1966. A quick test to determine lime requirements for lime stabilization. Highw. Res. Rec. 139, 61-72.

Gens, A., Nova, R., 1993. Conceptual bases for a constitutive model for bonded soils and weak rocks. Geotech. Eng. hard soils-soft rocks 1, 485-494.

Horpibulsuk, S., Liu, M.D., Liyanapathirana, D.S., Suebsuk, J., 2010a. Behaviour of cemented clay simulated via the theoretical framework of the Structured Cam Clay model. Comput. Geotech. 37, 1-9. doi:10.1016/j.compgeo.2009.06.007

Horpibulsuk, S., Rachan, R., Chinkulkijniwat, A., Raksachon, Y., Suddeepong, A., 2010 b. Analysis of strength development in cement-stabilized silty clay from microstructural considerations. Constr. Build. Mater. 24, 2011-2021. doi:10.1016/j.conbuildmat.2010.03.011

Lee, K., Chan, D., Lam, K., 2004. Constitutive model for cement treated clay in a critical state frame work. Soils Found. 44, 69-77. 
Leroueil, S., Vaughan, P.R., 1990. The general and congruent effects of structure in natural soils and weak rocks. Géotechnique 40, 467-488.

Little, D.N., 1995. Stabilization of pavement subgrades and base courses with lime, National Lime Association. Arlington.

Liu, M.D., Carter, J.P., 2002. A structured Cam Clay model. Can. Geotech. J. 39, 1313-1332. doi:10.1139/T02-069

Liu, M.D., Carter, J.P., 2003. Volumetric Deformation of Natural Clays. Int. J. Geomech. 3, 236-252. doi:10.1061/(ASCE)1532-3641(2003)3:2(236)

MacKenzie, R.C., 1970. Differential Thermal Analysis. Volume 1 $\square$ : Fundamental Aspects. Academic Press London, London-New York.

Mackenzie, R.C., 1972. Differential Thermal Analysis. Vol. 2. Applications., Academic P. ed. Academic Press London, London-New York.

Malandraki, V., Toll, D.G., 2001. Triaxial Tests on Weakly Bonded Soil with Changes in Stress Path. J. Geotech. Geoenvironmental Eng. 127, 282-291.

Maubec, N., 2010. Approche multi-echelle du traitement des sols a la chaux. Etudes des intéractions avec les argiles. Thèse de Doctorat, Université de Nantes, France.

Metelková, Z., Boháč, J., Přikryl, R., Sedlářová, I., 2012. Maturation of loess treated with variable lime admixture: Pore space textural evolution and related phase changes. Appl. Clay Sci. 61, 37-43. doi:10.1016/j.clay.2012.03.008

Muir Wood, D., 1991. Soil Behaviour and Critical State Soil Mechanics. 
North, J.M., Becker, J.G., Seagren, E.A., Ramirez, M., Peot, C., 2008. Methods for quantifying lime incorporation into dewatered sludge. I: Bench-scale evaluation. J. Environ. Eng. 134, 750-761.

508 Nova, R., Castellanza, R., Tamagnini, C., 2003. A constitutive model for bonded

509 geomaterials subject to mechanical and/or chemical degradation. Int. J. Numer. Anal.

$510 \quad$ methods Geomech. 27, 705-732.

511 Oliveira, P.J.V., Correia, A.A.S., Garcia, M.R., 2013. Effect of Stress Level and Binder

512 Composition on Secondary Compression of an Artificially Stabilized Soil. J. Geotech.

513 Geoenvironmental Eng. 139, 810-820. doi:10.1061/(ASCE)GT.1943-5606.0000762.

514 Pomakhina, E., Deneele, D., Gaillot, A.-C., Paris, M., Ouvrard, G., 2012. 29Si solid state

515 NMR investigation of pozzolanic reaction occurring in lime-treated Ca-bentonite. Cem.

516 Concr. Res. 42, 626-632. doi:10.1016/j.cemconres.2012.01.008

517 Rogers, C.D.F., Glendinning, S., 1996. The role of lime migration in lime pile stabilization of

518 slopes. Q. J. Eng. Geol. Hydrogeol. 29, 273-284.

519 doi:10.1144/GSL.QJEGH.1996.029.P4.02

520 Roscoe, K.H., Burland, J.B., 1968. On the generalized stress-strain behaviour of wet clay.

$521 \quad$ Eng. Plast. 535-609.

522 Rotta, G. V, Consoli, N.C., Prietto, P.D.M., Coop, M.R., Graham, J., 2003. Isotropic yielding 523 in an artificially cemented soil cured under stress. Géotechnique 53, 493-501.

524 doi:10.1680/geot.2003.53.5.493 
Saikia, N.J., Sengupta, P., Gogoi, P.K., Borthakur, P.C., 2002. Hydration behaviour of limeco-calcined kaolin-petroleum effluent treatment plant sludge. Cem. Concr. Res. 32, 297-302. doi:10.1016/S0008-8846(01)00676-7

Schofield, A.N., Wroth, C.P., 1968. Critical state soil mechanics. McGraw-Hill.

Stocker, P.T., 1974. Diffusion and diffuse cementation in lime and cement stabilised clayey soils - studies of plasticity and aggregation. Aust. Road Res. 5, 51-75.

Stoltz, G., Cuisinier, O., Masrouri, F., 2012. Multi-scale analysis of the swelling and shrinkage of a lime-treated expansive clayey soil. Appl. Clay Sci. 61, 44-51. doi:10.1016/j.clay.2012.04.001

Suebsuk, J., Horpibulsuk, S., Liu, M.D., 2010. Modified Structured Cam Clay: A generalised critical state model for destructured, naturally structured and artificially structured clays. Comput. Geotech. 37, 956-968. doi:10.1016/j.compgeo.2010.08.002

Suebsuk, J., Horpibulsuk, S., Liu, M.D., 2011. A critical state model for overconsolidated structured clays. Comput. Geotech. 38, 648-658. doi:10.1016/j.compgeo.2011.03.010

Thompson, M.R., 1965. Shear strength and elastic properties of lime-soil mixtures.

$$
\text { Washington. }
$$

Vatsala, A., Nova, R., Srinivasa Murthy, B.R., 2001. Elastoplastic Model for Cemented Soils. J. Geotech. Geoenvironmental Eng. 127, 679-687.

Wissa, A.E.Z., 1965. Effective stress-strength behavior of cemented soils. Thesis (Sc. D.), Massachusetts Institute of Technology. 
545 Zhu, W., Zhang, C.L., Chiu, A.C.F., 2007. Soil-Water Transfer Mechanism for Solidified

546 Dredged Materials. J. Geotech. Geoenvironmental Eng. 133, 588-598.

547 doi:10.1061/(ASCE)1090-0241(2007)133:5(588)

548

549 
Table 1: Characteristics of the silt

\begin{tabular}{|c|c|}
\hline Geotechnical properties & Value \\
\hline Liquid Limit LL (\%) & 31.2 \\
\hline Plastic Limit PL (\%) & 7.8 \\
\hline Plasticity Index PI & 23.4 \\
\hline Particle Density $\rho_{S}\left(\mathrm{Mg} \cdot \mathrm{m}^{-3}\right)$ & 2.66 \\
\hline Methylene Blue Value ( $\mathrm{g} / 100 \mathrm{~g}$ of dry soil) & 2.1 \\
\hline $\mathrm{USCS}^{\mathrm{a}}$ & ML \\
\hline \multicolumn{2}{|l|}{ Physical chemistry properties } \\
\hline $\mathrm{pH}(-)$ & 5.7 \\
\hline Cation-Exchange Capacity $(\mathrm{cmol}+/ 100 \mathrm{~g})$ & 7.41 \\
\hline Carbonate Mass Concentration (\%) & 0.6 \\
\hline \multicolumn{2}{|l|}{ Initial conditions } \\
\hline Dry density $\left(\mathrm{Mg} \cdot \mathrm{m}^{-3}\right)$ & 1.68 \\
\hline Water content $w(\%)$ & 20 \\
\hline Initial void ratio $e_{i}(-)$ & 0.6 \\
\hline
\end{tabular}


Table 2: Results of Proctor compression test for different concentrations in lime

\begin{tabular}{ccc}
\hline $\begin{array}{c}\text { Lime content } \\
(\%)\end{array}$ & $\begin{array}{c}\text { Optimal moisture content } \\
(\%)\end{array}$ & $\begin{array}{c}\text { Optimal dry density } \\
\left({\left.\mathrm{Mg} . \mathrm{m}^{-3}\right)}^{-}\right.\end{array}$ \\
\hline 0 & 17.9 & 1.76 \\
1 & 18.8 & 1.72 \\
2 & 20.3 & 1.68 \\
3 & 20.9 & 1.64 \\
\hline
\end{tabular}


Table 3: Saturation stages performed

\begin{tabular}{lccc}
\hline & Stage 1 & Stage 2 & Stage 3 \\
\hline Duration (Days) & $\approx 7$ & $\approx 7$ & $\approx 7$ \\
\hline$\sigma_{3}(\mathrm{kPa})$ & 50 & 100 & 200 \\
$P_{\text {bottom }}(\mathrm{kPa})$ & 30 & 80 & 180 \\
$P_{\text {top }}(\mathrm{kPa})$ & 20 & 70 & 170 \\
\hline$\overline{\sigma_{3}^{\prime}}(\mathrm{kPa})$ & 25 & 25 & 25 \\
\hline$P_{\text {bottom }}:$ Pressure at the bottom of the specimen $-P_{\text {top }}:$ Pressure at the top of the specimen
\end{tabular}


Table 4: Characteristics of the specimens

\begin{tabular}{ccccc}
\hline Lime content $(\%)$ & Water content $(\%)$ & $\rho_{\mathrm{d}}\left(\mathrm{Mg}^{-\mathrm{m}^{-3}}\right)$ & $\mathrm{e}_{0}(-)$ & $\begin{array}{c}\text { Hydraulic } \\
\text { Permeability k }(\mathrm{m} / \mathrm{s})\end{array}$ \\
\hline 0 & 20.0 & $1.67 \pm 0.01$ & $0.60 \pm 0.02$ & $10^{-9}-10^{-8}$ \\
0.5 & 19.6 & $1.67 \pm 0.01$ & $0.60 \pm 0.01$ & $10^{-9}-10^{-8}$ \\
1 & 20.2 & $1.67 \pm 0.01$ & $0.60_{ \pm} 0.01$ & $10^{-9}-10^{-8}$ \\
2 & 19.6 & $1.67 \pm 0.01$ & $0.60_{ \pm} 0.01$ & $10^{-8}-10^{-7}$ \\
5 & 20.2 & $1.66 \pm 0.01$ & $0.60 \pm 0.02$ & $10^{-8}-10^{-7}$ \\
\hline
\end{tabular}


Table 5: Ranges of temperatures used for the determination of the TGA/DTA

\begin{tabular}{cc}
\hline Range of temperature & Chemical compound \\
\hline $20^{\circ} \mathrm{C}-217^{\circ} \mathrm{C}$ & Free and adsorbed water \\
$217^{\circ} \mathrm{C}-350^{\circ} \mathrm{C}$ & Cementitious compounds \\
$350^{\circ} \mathrm{C}-610^{\circ} \mathrm{C}$ & Portlandite $\left(\mathrm{Ca}(\mathrm{OH})_{2}\right)$ \\
$610^{\circ} \mathrm{C}-800^{\circ} \mathrm{C}$ & Carbonates $\left(\mathrm{CaCO}_{3}\right)$ \\
\hline
\end{tabular}


Table 6: Influence of lime on the mechanical properties

\begin{tabular}{lccccc}
\hline \multirow{2}{*}{ Parameters } & \multicolumn{5}{c}{ Values } \\
\cline { 2 - 6 } & $0 \%$ & $0.5 \%$ & $1 \%$ & $2 \%$ & $5 \%$ \\
\hline$p_{y}^{\prime}(\mathrm{kPa})$ & 177 & 300 & 731 & 1,211 & 1,691 \\
$v_{0}$ & 1.602 & 1.609 & 1.612 & 1.606 & 1.626 \\
$\lambda$ & 0.075 & 0.088 & 0.085 & N/A & N/A \\
$\kappa$ & 0.005 & 0.005 & 0.005 & 0.005 & 0.005 \\
$M$ & 1.092 & N/A & 1.136 & 1.246 & 1.464 \\
$\varphi\left({ }^{\circ}\right)$ & 27.5 & N/A & 28.5 & 31.1 & 36.0 \\
$\mathrm{c}(\mathrm{kPa})$ & 11.4 & N/A & 47.9 & 152.9 & 207.6 \\
\hline
\end{tabular}

$c$ : Cohesion, $\varphi$ : angle of friction 
Table 7: Optimal set of parameters for a logistic interpolation

\begin{tabular}{cccccc}
\hline Parameter & $p_{y, \min }$ & $p_{y, \max }$ & $\beta$ & $\Delta x$ & $\mathrm{R}^{2}$ \\
\hline Value & 100 & 2,000 & 17.4 & 0.16 & 0.95 \\
\hline
\end{tabular}


Table 8: Parameters for the Structured Cam Clay model adapted for lime treated soils

\begin{tabular}{cccccc}
\hline MSCC & \multicolumn{5}{c}{ Lime content } \\
\cline { 2 - 6 } parameters & $0 \%$ & $0.5 \%$ & $1 \%$ & $2 \%$ & $5 \%$ \\
\hline$b$ & 0.0 & 1.8 & 7.2 & - & - \\
$\Delta e_{i}$ & 0.0 & 0.027 & 0.066 & 0.129 & 0.159 \\
$\Delta e_{c}$ & 0.0 & 0.0 & 0.046 & - & - \\
\hline \multicolumn{7}{c}{ MSCC. Modified Structured Cam Clay }
\end{tabular}

MSCC: Modified Structured Cam Clay 
Figure 1: TGA/DTA results for a lime treated specimen with the three temperatures domains

- Hyd.: Hydrates, DTG: Differential Thermo Gravimetric, TGA: Thermo Gravimetric Analysis

Figure 2: Isotropic consolidation curves for five concentrations in lime

Figure 3: Evolution of the yield stress after 28 days of curing with the lime

Figure 4: Drained triaxial results on $0 \%$ and $5 \%$ lime treated specimens $-\varepsilon_{p}$ : volumetric deformations, $\varepsilon_{a}$ : axial strain, $q$ : deviatoric stress

Figure 4a: Shear behaviour for untreated specimens

Figure 4b: Shear behaviour for $5 \%$ lime treated specimens

Figure 5: Yield loci and critical states of $0 \%, 1 \%, 2 \%$, and $5 \%$ lime treated specimens YL: yield loci, CS : Critical State, M: Gradient of critical state line 
Figure 6: Influence of a lime treatment on the variation of the mass concentration in hydrates (cementitious compounds), portlandite, and carbonates for a curing time of 28 days. $-\Delta m_{p}$ : Mass concentration in portlandite, $\Delta m_{h}$ : Mass concentration in hydrates,$\Delta m_{c}$ : Mass concentration in carbonates.

Figure 7: Scatterplot matrix between the yield stress and the mass concentrations in cementitious compounds, portlandite, and carbonates.

Figure 8: Logistic interpolation for a chemo-mechanical coupling $-\Delta m_{h}$ : Mass concentration in hydrates

Figure 9: Isotropic compression for $0 \%$ and $1 \%$ lime treated specimens - MSCC : Modified Structured Cam Clay; $\Delta e_{i}$ : Additional void ratio at yield ; $\Delta e_{c}$ : Vertical translation of the virgin compression line. 
Click here to download Figure: Figure 2.pdf

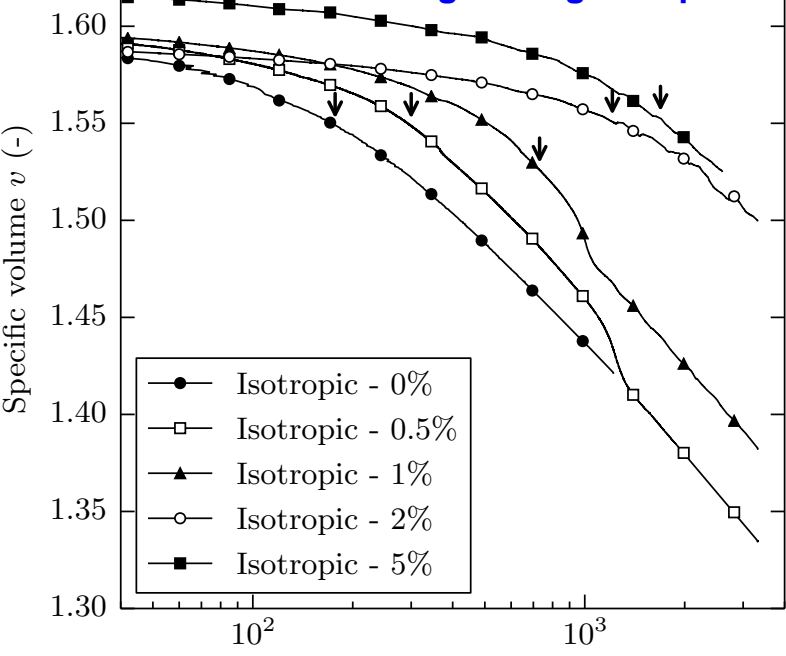

Mean effective stress $p^{\prime}(\mathrm{kPa})$ 


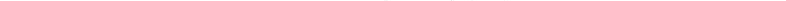


Clicks here to download Figure: Figure 4a.pedf
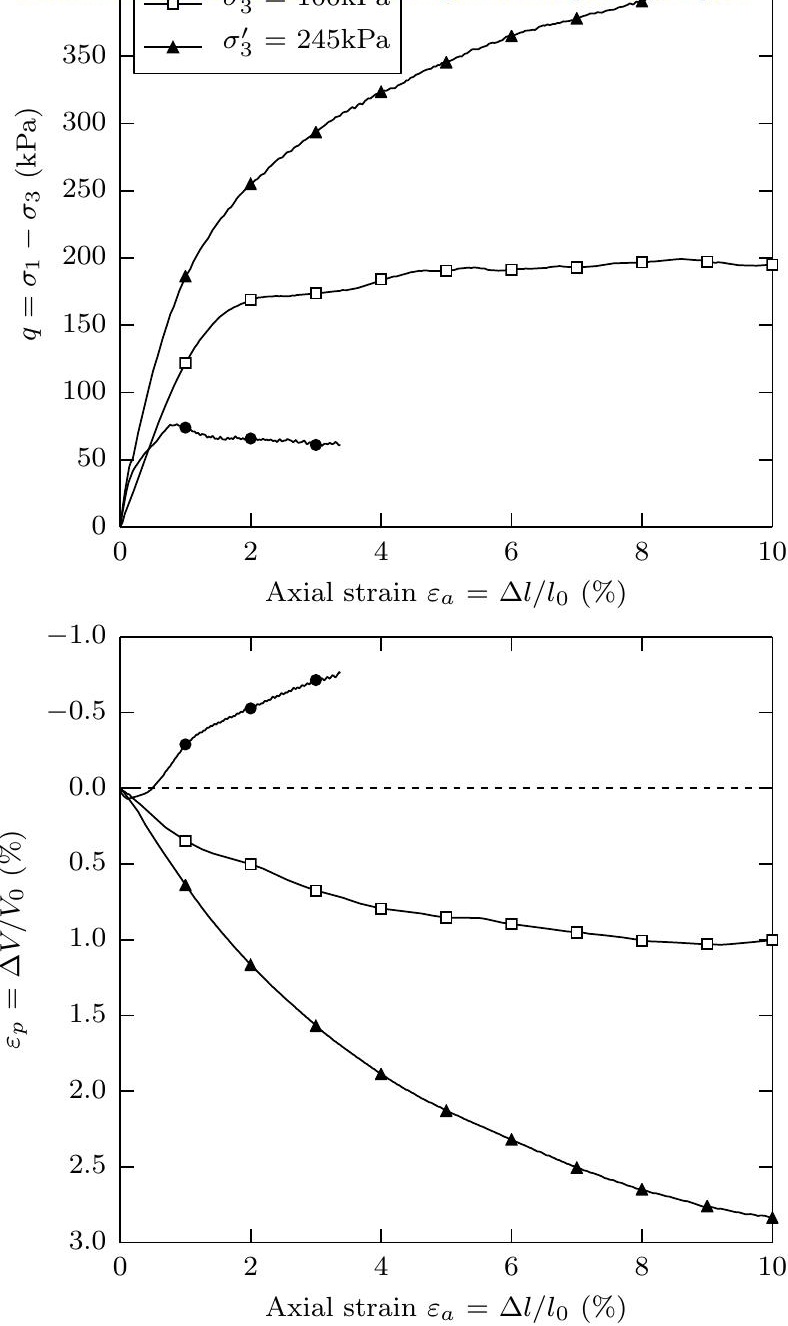


\section{Click here to download Figure: Figure 4b.pdf}
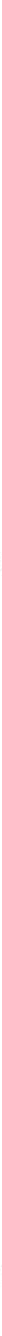


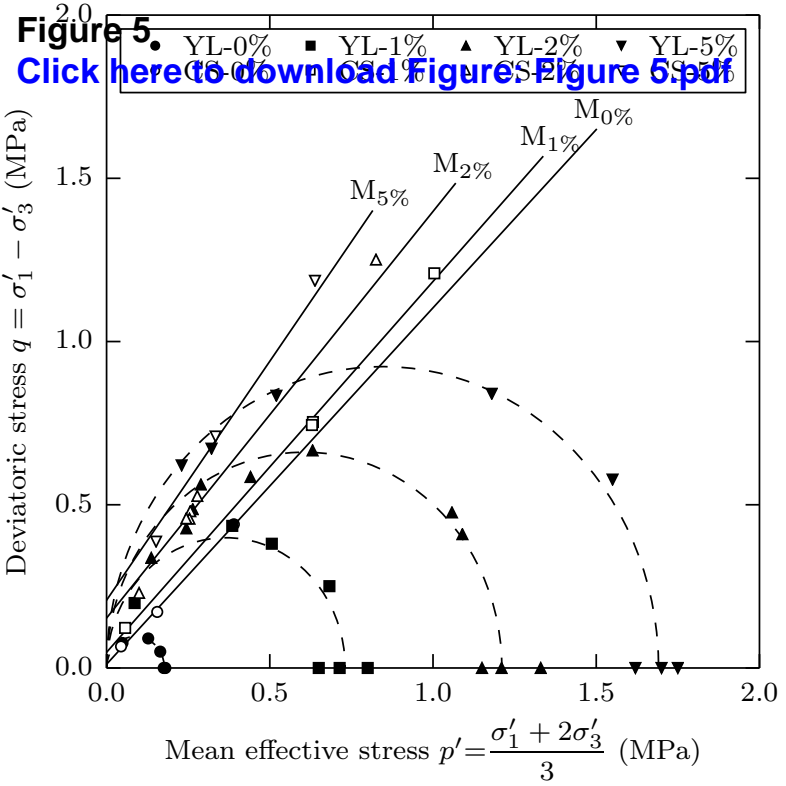




\section{Figure 7 \\ (\%)

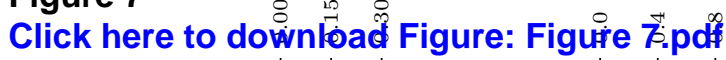

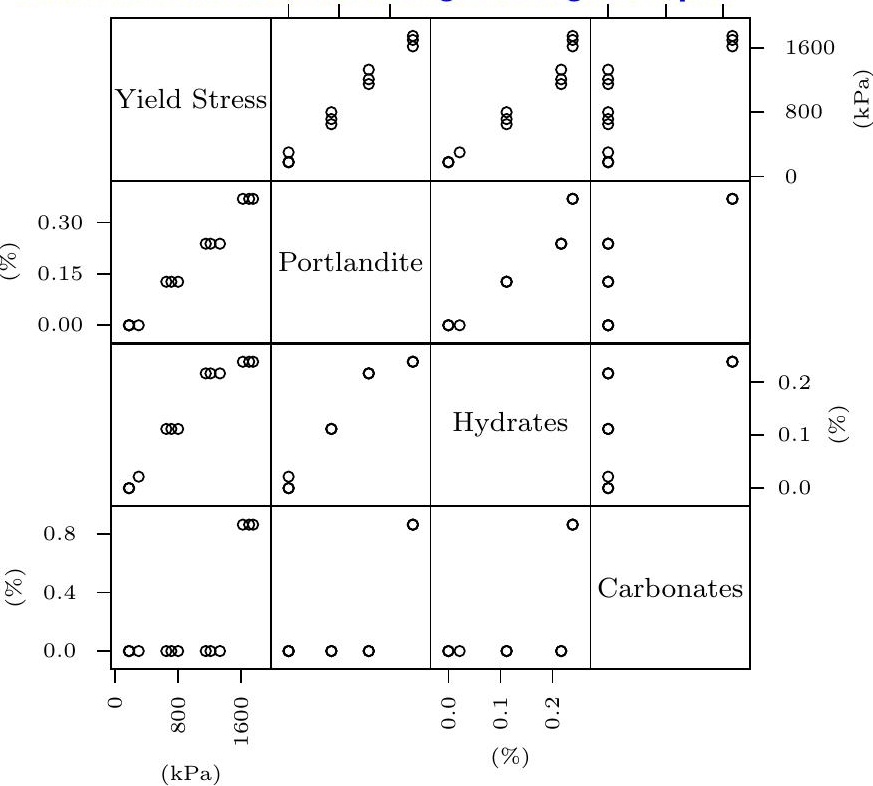




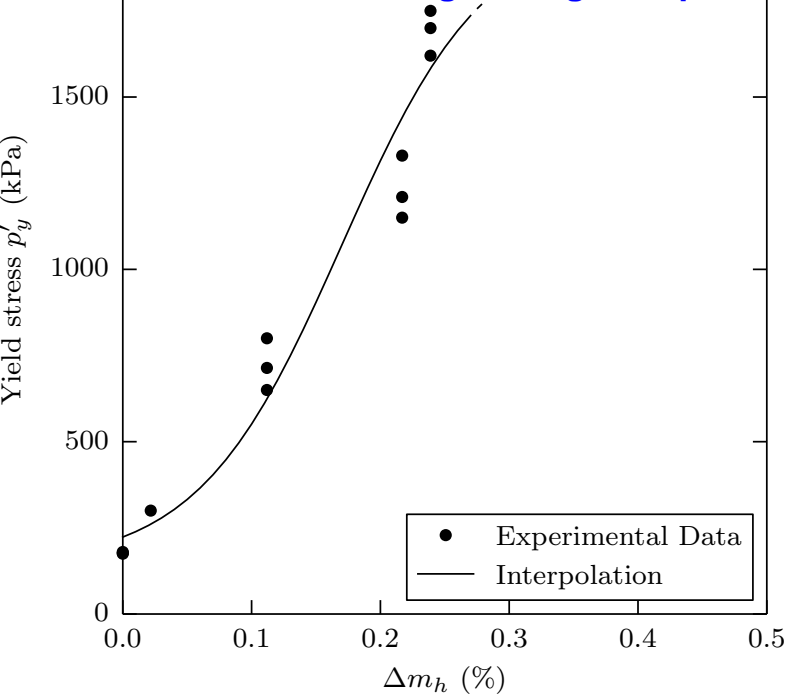


